\title{
sala

\section{USO DE APRENDIZAGEM BASEADA EM PROBLEMAS NO ENSINO DE FÍSICA NO ENSINO DE JOVENS E ADULTOS}

\section{USE OF PROBLEM-BASED LEARNING IN PHYSICS TEACHING IN A YOUTH AND ADULT EDUCATION}

\author{
Renata Perozini \\ Programa de Pós-Graduação em Ensino de Ciências e Matemática \\ Instituto Federal do Espírito Santo \\ E-mail: rperozini@gmail.com \\ Marize Lyra Silva Passos \\ Instituto Federal do Espírito Santo, Cefor \\ E-mail: marize@ifes.edu.br \\ Rafaela Gomes Bravo \\ Programa de Pós-Graduação em em Educação Profissional e Tecnológica \\ Instituto Federal do Espírito Santo \\ E-mail: rafaela_gbravo@hotmail.com \\ Isaura Alcina Martins Nobre \\ Instituto Federal do Espírito Santo \\ E-mail: Isaura.ead@gmail.com
}

\begin{abstract}
Resumo: O uso de metodologias ativas vem ganhando espaço na educação brasileira, inclusive no ensino de jovens e adultos, modalidade que objetiva oferecer educação a jovens e adultos que não concluíram seus estudos ou não tiveram o acesso ao Ensino Fundamental ou Médio na idade apropriada. Esses alunos, já adultos, trazem uma grande bagagem vivencial, o que desafia os professores a trazerem para as salas de aula estratégias pedagógicas mais significativas que os coloquem no centro do processo. Entre as diversas estratégias conhecidas pode-se citar o uso da aprendizagem baseada em problemas ( $A B P$ ), estratégia escolhida para o ensino de física em uma turma de ensino médio de Jovens e Adultos de uma escola pública. Este trabalho foi a primeira etapa de uma pesquisa de mestrado e irá descrever os passos do planejamento e da aplicação da estratégia pedagógica ABP intitulado "Uma Volta ao Espaço em Trinta Dias".
\end{abstract}

Palavras-chave: Metodologias Ativas. Aprendizagem Baseada em Problemas. Ensino de Jovens e Adultos.

Abstract: The use of active learning methodologies has been gaining ground in Brazilian education, including youth and adult education. This modality aims to provide education for young and adult students who have not completed their studies or did not have access to elementary or secondary school at the appropriate age. These students are adults, and bring a great deal of experience, which challenges teachers to bring to the classroom more significant pedagogical strategies that put them at the center of the process. Among the various strategies that have this focus, we can mention the use of problem-based learning (PBL), which was the strategy chosen for teaching physics for a youth and adult class. It will describe the steps of planning and implementing the PBL pedagogical strategy entitled "Uma Volta ao Espaço em Trinta Dias."

Keywords: Active Learning Methodologies. Problem-based Learning. Youth and Adult Education. 


\section{sala \\ de $\oplus$ em \\ aula foco}

\section{INTRODUÇÃO}

Os professores do século XXI precisam repensar suas práticas pedagógicas, renovando as formas de contextualização para motivar o aluno a ter interesse pelo estudo das ciências. As metodologias ativas da aprendizagem vêm ao encontro desta nova visão que coloca o aluno no centro do processo educativo e, se constituem um dos meios utilizados para pensar a educação de forma inovadora, facilitando o processo de aprendizagem e tornando-o prazeroso.

Mattar (2017) afirma existirem diversas estratégias de metodologias ativas, que podem ser utilizadas em ambientes educativos para auxiliar o protagonismo dos alunos, tais como: a sala de aula invertida; a instrução por pares; a aprendizagem baseada em problemas; a aprendizagem baseada em projetos; aprendizagem baseada em jogos e gamificação; design thinking etc. Neste trabalho será dado foco a aprendizagem baseada em problemas (APB) que teve sua origem no Curso de Medicina da McMaster University's Faculty of Health Sciences no Canadá, no ano de 1965 (CAPLOW et al., 1997). Na APB os alunos não resolvem um problema, mas, passam a "[...] usá-la para identificarem suas próprias necessidades de aprendizagem à medida que tentam entendê-lo, reunir, sintetizar e aplicar informações ao problema e começar a trabalhar efetivamente para aprender com os membros do grupo e tutores [...]" (MATTAR, 2017, p. 55).

As características citadas anteriormente fazem do uso da ABP uma boa estratégia pedagógica a ser utilizada com alunos da Educação de Jovens e Adultos (EJA), uma vez que suas políticas devem ser abrangentes, diversificadas e altamente flexíveis, que na visão de Di Pierro, Joia e Ribeiro (2001), deve levar em conta três pontos fundamentais: à autonomia dos sujeitos em traçar sua biografia formativa; oferta educativa a partir de modalidades diversificadas, visando atender a todos em sua diversidade e, por fim, reconhecer os conhecimentos adquiridos pelos alunos fora da escola, isto é, valorizar os saberes experienciais dos estudantes.

Este trabalho se propõe, então, a descrever o planejamento e uso da ABP no ensino de física, na disciplina da área de ciências da natureza (física, química, biologia), para alunos matriculados na segunda etapa do ensino médio de Jovens e adultos de uma escola pública no estado do Espírito Santo. 


\section{sala \\ de $\oplus$ em \\ aula foco}

\section{EDUCAÇÃO DE JOVENS E ADULTOS (EJA)}

A Educação de Jovens e Adultos (EJA) é uma modalidade de ensino definida na Lei de Diretriz e Bases da Educação, Lei no 9.394, de 20 de dezembro de 1996 (LDB), que perpassa todos os níveis da Educação Básica do país. Essa modalidade destina-se a atender aos jovens, adultos e idosos que não tiveram acesso à educação na escola convencional na idade apropriada.

A concepção da EJA defende o direito do jovem e adulto a uma educação digna de acordo com as especificidades do seu ciclo de formação, ou seja, "[...] direito à vivência plena e a garantia de processos educativos que vão além da escolarização e que levem em consideração a vivência dessas pessoas no trabalho, na cultura, os aprendizados que já possuem [...]" (SILVA, 2009, p. 63).

Di Pierro, Joia e Ribeiro (2001, p. 71) citam três pontos fundamentais associados aos alunos da EJA que devem ser observados na oferta de cursos: flexibilização da organização curricular; oferta de múltiplos meios de ensino-aprendizagem e aperfeiçoamento dos mecanismos de avaliação.

\footnotetext{
- Flexibilizar a organização curricular e assegurar certificação equivalente para percursos formativos diversos, facultando aos indivíduos que autodeterminem suas biografias educativas, optando pela trajetória mais adequada às suas necessidades e características;

- Prover múltiplas ofertas de meios de ensino-aprendizagem, presenciais ou a distância, escolares e extra-escolares, facultando a circulação e o aproveitamento de estudos nas diferentes modalidades e meios;

- Aperfeiçoar os mecanismos de avaliação, facultar a creditação de aprendizagens adquiridas na experiência pessoal e/ou profissional ou por meio de ensinos não-formais, diversificando e flexibilizando os meios de acesso a níveis de escolaridade mais elevados (DI PIERRO; JOIA; RIBEIRO, 2001, p. 71-72).
}

Outro ponto importante de ser levado em conta é a heterogeneidade do público da EJA, essa constatação se faz necessária para que se possa compreender o enorme desafio posto aos professores das mais diversas áreas ao atuarem nesta modalidade de ensino, pois nesse caso, encontrar um ponto convergência que se convencione como conhecimento prévio de todos os alunos, pode ser tarefa extremamente complicada.

É muito comum encontrar nos discursos, pesquisas e práticas, referências às "pessoas jovens e adultas" como se os dois grupos formassem um mesmo contingente de estudantes, ou até mesmo houvesse a diluição da juventude da EJA na vida adulta. Portanto, deve-se tomar cuidado para não homogeneizar o público da EJA como se este constituísse um bloco indiferenciado (SILVA, 2009, p. 66). 


\section{sala \\ de $\oplus$ em \\ aula foco}

Boa parte dos alunos da EJA possui defasagem significativa da educação básica, o que dificulta o uso de recursos tradicionais bastante adotados pelas instituições de ensino, como a indicação de leituras prévias de conteúdo em artigos, livros e congêneres; das avaliações discursivas e que demandem excelência em interpretação de texto até mesmo para identificar o que é pedido em seu cabeçalho, e de acompanhar aulas expositivas que exigem que o aluno domine o vocabulário muitas vezes demasiadamente rebuscado do docente.

Além disso, na visão de Di Pierro, Joia e Ribeiro (2001, p. 69), "a demanda pelo ensino fundamental de jovens e adultos é extensa e complexa [...]", e para enfrentar esses desafios, as metodologias ativas de aprendizagem, podem representar alternativa interessante para que o docente se aproxime da realidade social dos alunos da EJA, permitindo que estes tomem as rédeas do seu processo de aprendizagem. As metodologias de aprendizagem ativa incentivam os alunos a construírem o seu próprio conhecimento de forma autônoma.

\section{APRENDIZAGEM BASEADA EM PROBLEMAS (ABP)}

A ABP como uma das estratégias de metodologias ativas de aprendizagem, pode ser um dos meios utilizados para pensar a educação de forma inovadora, podendo ser aplicada nos mais diversos contextos educacionais visando motivar os alunos, bem como engaja-los nas propostas didáticas, além de formar cidadãos capazes de solucionar problemas e, levar os "[...] alunos a aplicação de atividades de análise, síntese e avaliação da informação, em vez de simplesmente exigir alguma resposta" (MUNHOZ, 2015, p. 84).

O sucesso da ABP tem como mote a resolução de um problema desconhecido e possivelmente intrigante, que desafie o desenvolvimento de suas habilidades de resolução de problemas além de estimular uma aprendizagem autodirigida relevante. Para Barrows e Tamblyn (1980), um problema pode servir como um ponto de partida para estudantes de várias áreas desenvolverem uma compreensão das preocupações e habilidades e desenvolver um trabalho colaborativo.

Mas, encontrar a resposta para uma pergunta não é ABP, usar um princípio ou solução conhecida para explicar uma observação ou fenômeno não é ABP. Problemas podem ser usados para 


\section{sala \\ de $\oplus$ em \\ aula foco}

REVISTA ELETRÔNICA

estimular raciocínio e aprendizagem (BARROWS; TAMBLYN, 1980). Para estes mesmos autores o método ABP deve ser analisado por quatro fatores essenciais: o tipo de problema utilizado; as sequências de ensino-aprendizagem; as responsabilidades dadas aos estudantes para aprendizagem; os métodos para a avaliação dos alunos.

Para Walker et al. (2015) o tipo de problema utilizando na ABP devem ser moderadamente mal estruturadas de forma que permita o inquérito livre. Problemas no mundo real são mal estruturados (ou não seriam problemas). Uma habilidade crítica desenvolvida através do método ABP é a capacidade de identificar o problema e parâmetros no desenvolvimento de uma solução. Quando um problema é bem estruturado os alunos são menos motivados.

Já as sequências de ensino-aprendizagem utilizadas devem ser integradas a partir de uma ampla gama de disciplinas ou assuntos. Segundo Walker et al. (2015) conceitos específicos que fazem parte dos objetivos do problema em questão, é denominado espaço do problema, porém o autor também apresenta a ideia do espaço conceitual relacional (CR) que é maior do que o espaço do problema do diagnóstico correto e abrange explicações alternativas.

Para Munhoz (2015) o trabalho desenvolvido na ABP leva os alunos a planejar e organizar de forma mais cuidadosa diversos aspectos: o tempo gasto, o local de aprendizagem, escolha do local da pesquisa, seleção de informações e a sua utilização para resolver problemas que, junto com seu grupo, foi determinado como necessário para aprender o conteúdo previsto. Promovendo uma aprendizagem autodirigida, na qual os alunos devem ser capazes de acessar, estudar e integrar informações de todas as disciplinas que possam estar relacionadas como o problema em particular.

E, por fim, Barrows e Tamblyn (1980) defendem que a ABP requer diferentes tipos de ferramentas de exame que avaliam a capacidade do aluno de trabalhar com problemas e aplicar a informação aprendida à sua compreensão ou resolução.

\section{UMA VOLTA AO ESPAÇO EM TRINTA DIAS}

O projeto baseado no uso da ABP intitulado "Uma Volta ao Espaço em Trinta Dias" foi realizado em uma escola pública em uma turma de 2o etapa do EJA Ensino Médio, semipresencial, noturno. A 


\section{sala \\ de $\oplus$ em \\ aula foco}

disciplina de física possui semanalmente 1 hora de aula presencial e 1 hora não presencial, perfazendo uma carga horária presencial de 20h, e mais 20h não presencial que pode ser avaliada através de trabalhos e atividades sugeridos pelo professor e que serão entregues presencialmente.

Os alunos foram informados sobre os objetivos e às atividades propostas na intervenção didática, bem como seus benefícios e riscos. Esses foram convidados a participar voluntariamente da pesquisa, assinando um Termo de Consentimento Livre e Esclarecido (TCLE). Entre os participantes, 10 são do sexo feminino e 14 do sexo masculino, com idades que variam de 18 a 42 anos. Aqui vale ressalva à heterogênea do grupo, formado por indivíduos com conhecimentos prévios e vivências diversas, o que, se bem utilizado podem propiciar benefício ao processo.

As atividades ligadas à metodologia $\mathrm{ABP}$ se desenvolveram no primeiro semestre do ano de 2019 . A turma escolhida apresentava um número elevado de desistência em relação às outras cinco turmas de EJA da escola, pois dos quarenta alunos matriculados apenas vinte quatro alunos frequentavam a escola regularmente, e estes aceitaram prontamente a participar da intervenção.

A seguir serão descritas, na fase de planejamento e aplicação da APB no projeto descrito neste trabalho, os quatro fatores essenciais da metodologia descritos por Barrows e Tamblyn (1980).

\subsection{TIPO DE PROBLEMA UTILIZADO}

A etapa da escolha do problema mereceu bastante atenção, uma vez que, segundo Barrows e Tamblyn (1980), o problema não pode conter uma resposta que já tenha sido elaborada, pois, desta forma, o problema se reduziria a uma pesquisa. Pensamos em um problema moderadamente mal estruturado, e com um grau de dificuldade não tão elevado a ponto de desmotivar o aluno, dentro da temática Terra e Universo.

O Problema proposto foi: "Supondo-se vencedor de um concurso mega bilionário e tendo viajado todos os continentes, você resolve fazer um passeio diferente, dar uma volta ao espaço. Como seria a programação dessa viagem?" e baseamos nos critérios descritos por Walker et al. (2015) para mapear o grau de complexidade e a estruturação do problema, foi feita uma avaliação prévia pelos pesquisadores sobre a adequação do problema proposto a $A B P$, apresentamos os resultados dessa 


\section{sala \\ de $\oplus$ em \\ aula foco}

avaliação no Quadro 1.

Quadro 1 - Avaliação das pesquisadoras relativa à complexidade e estruturação do problema de ABP adotado.

\begin{tabular}{|c|c|c|c|c|c|}
\hline COMPLEXIDADE DO PROBLEMA & 1 & 2 & 3 & 4 & 5 \\
\hline $\begin{array}{l}\text { Amplitude do conhecimento (número de conhecimentos e informações envolvidos no processo } \\
\text { de resolução). }\end{array}$ & & & & & $\mathrm{x}$ \\
\hline $\begin{array}{l}\text { Nível de dificuldade em aplicar e compreender os conceitos envolvidos (quanto os conceitos } \\
\text { são difíceis para os alunos entenderem). }\end{array}$ & & & $\mathrm{x}$ & & \\
\hline $\begin{array}{l}\text { Nível de habilidade e conhecimento necessários na resolução (inclui o número de etapas a } \\
\text { serem executadas em uma solução). }\end{array}$ & & & $\mathrm{x}$ & & \\
\hline $\begin{array}{l}\text { Grau de não-linearidade (número de relações que precisam ser processadas em paralelo } \\
\text { durante a solução de problemas). }\end{array}$ & & & & & $\mathrm{x}$ \\
\hline ESTRUTURAÇÃO DO PROBLEMA & 1 & 2 & 3 & 4 & 5 \\
\hline Intransparência (ocorre quando o solucionador recorre a suposições ou adivinhações). & & & & $\mathrm{x}$ & \\
\hline $\begin{array}{l}\text { Heterogeneidade de interpretações (número de possíveis interpretações e perspectiva para } \\
\text { entender e resolver o problema). }\end{array}$ & & $\mathrm{x}$ & & & \\
\hline $\begin{array}{l}\text { Interdisciplinaridade problemas reais é de natureza interdisciplinar (não pode ser resolvido } \\
\text { considerando apenas uma perspectiva disciplinar). }\end{array}$ & & & $\mathrm{x}$ & & \\
\hline $\begin{array}{l}\text { Dinamicidade (existem variáveis em um problema que só aparecem em respostas às mudanças } \\
\text { de outras variáveis). }\end{array}$ & & $\mathrm{x}$ & & & \\
\hline $\begin{array}{l}\text { Legitimidade de alternativas competitivas (medida em que o número de soluções aceitáveis e } \\
\text { caminhos de solução existem dentro do espaço do problema) }\end{array}$ & & & $\mathrm{x}$ & & \\
\hline
\end{tabular}

Fonte: Compilado e elaborado pelas autoras (2019).

Com base nos nove parâmetros analisados supomos que o problema está ligeiramente acima da média da complexidade e moderadamente mal estruturado o que indica um nível pretendido para a aplicação do problema. Então foi dado procedimento a ABP.

Para compor o cenário foi apresentada aos alunos uma reportagem, exibida no canal de televisão aberta Band, em um programa de jornalismo, com duração de cinco minutos. Esta reportagem foi exibida na televisão em março de 2019, com o título "Turismo Espacial: Cápsula da Spacex é testada com sucesso". Após o vídeo ocorreu uma palestra sobre o sistema Sol-Terra-Lua, na qual foi apresentado: as estações do ano, as fases da Lua e os eclipses. Ao final da palestra ocorreu uma demonstração sobre a utilização do aplicativo de planetário Stellarium. A palestra foi realizada pela equipe, Gaturamo Observatório Astronômico - GOA, ligada ao departamento de física da Universidade Federal do Espírito Santo, que faz parte do projeto telescópio nos bairros.

Finalizada a palestra os alunos tiveram a oportunidade de manipular o telescópio para observação 


\section{sala \\ de $\oplus$ em \\ aula 1 foco}

dos astros. Esse momento propiciou um bate-papo sobre a observação celeste, desvendando curiosidades comuns aos alunos.

Figura 1 - Algumas imagens registradas durante a palestra.
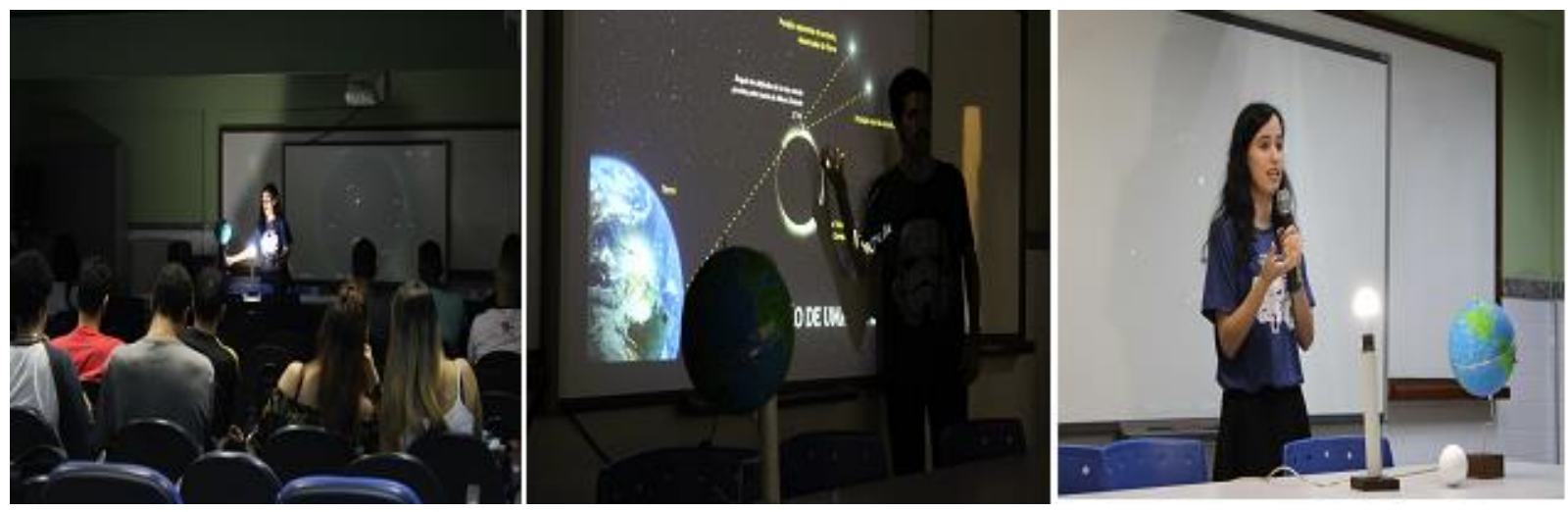

Fonte: Acervo da autora (2019).

Finalizada a palestra os alunos tiveram a oportunidade de manipular o telescópio para observação dos astros. Esse momento propiciou um bate-papo sobre a observação celeste, desvendando curiosidades comuns aos alunos.

\subsection{SEQUÊNCIAS DE ENSINO-APRENDIZAGEM}

Foi elaborada uma sequência didática intitulada "Uma Volta ao Espaço em Trinta Dias" orientada pela metodologia da ABP, com a finalidade de observar situações de aprendizagem. Esse planejamento foi avaliado por dez professores voluntários com base no instrumento de análise, avaliação e validação do planejamento de ABP, adaptado de Amado (2014).

Das dezesseis questões avaliadas, quatorze receberam notas positivas (4 ou 5) e duas categorias nota neutra (3) e nenhuma categoria recebeu notas negativas (1 e 2). Então o instrumento de análise, avaliação e validação do nosso planejamento de ABP nos indica uma aprovação pelos avaliadores externos. Como visto no Quadro 2. 


\section{sala \\ de $\oplus$ em \\ aula foco}

Quadro 2 - Resumo das avaliações

\begin{tabular}{|c|c|c|c|c|c|}
\hline QUESTÃO & 1 & 2 & 3 & 4 & 5 \\
\hline $\begin{array}{l}\text { Tema: O tema proposto tem como ponto principal a contextualização para o desenvolvimento de } \\
\text { um conteúdo científico que sirva como elemento explicativo de determinada situação. }\end{array}$ & & & & & 10 \\
\hline $\begin{array}{l}\text { Contextualização Curricular: O tema proposto está presente no currículo (federal, estadual ou } \\
\text { municipal) de ciências? }\end{array}$ & & & & & 10 \\
\hline Tempo: O tempo designado é condizente com as atividades elencadas no ciclo tutorial? & & & 2 & 4 & 4 \\
\hline $\begin{array}{l}\text { Pré-requisitos: Os conteú dos propostos estão respeitando os pré-requisitos conceituais relativos } \\
\text { à faixa etária e série? }\end{array}$ & & & & 2 & 8 \\
\hline $\begin{array}{l}\text { Objetivos Específicos: Os objetivos são claramente informados? Estes se vinculam com a } \\
\text { problemática e os conceitos apresentados? Estão efetivamente direcionados a aprendizagem dos } \\
\text { conteúdos e conceitos propostos? }\end{array}$ & & & & 1 & 9 \\
\hline $\begin{array}{l}\text { Articulaçōes Disciplinares: A proposta da ABP tem articulação entre diferentes disciplinas? Ou } \\
\text { pelo menos busca articular diferentes conceitos dentro da mesma disciplina? }\end{array}$ & & & & & 10 \\
\hline $\begin{array}{l}\text { Conceitos: Existe estreita relação entre a problemática do cenário e os conceitos científicos? O } \\
\text { conhecimento dos conceitos é capaz de responder o problema apresentado, para que se } \\
\text { alcancem os objetivos que tal ABP se propõe? }\end{array}$ & & & & 1 & 9 \\
\hline $\begin{array}{l}\text { Cenário: A escolha e formulação do problema central do cenário foram construídas segundo a } \\
\text { temática proposta? A temática é atual? A resolução de tal problema, conforme apresentado, é ou } \\
\text { torna-se (no desenrolar do cenário) uma necessidade? O cenário motivará os alu nos? }\end{array}$ & & & & & 10 \\
\hline $\begin{array}{l}\text { Levantamento de Questōes-problema: as questões problema levantadas pelo professor são } \\
\text { coerentes com os objetivos propostos? }\end{array}$ & & & & & 10 \\
\hline $\begin{array}{l}\text { Produto Final: O produto final é resultado de todo trabalho de investigação? Apresentam as } \\
\text { soluções encontradas para as questões-problema formuladas no âmbito do cenário proposto? }\end{array}$ & & & & & 10 \\
\hline $\begin{array}{l}\text { Fonte de Dados: A bibliografia indicada pelo professor permite aos alunos uma consulta/leitura } \\
\text { proveitosa para resolver as questões-problema apresentadas? }\end{array}$ & & & & & 10 \\
\hline $\begin{array}{l}\text { Passos do Ciclo Tutorial: Os passos do ciclo tutorial são adequados e suficientes para alcançar os } \\
\text { objetivos planejados? As estratégias didáticas são diversificadas e a propriadas para o } \\
\text { desenvolvimento da problemática proposta? }\end{array}$ & & & & 2 & 8 \\
\hline Aplicação: Após a investigação os alunos são capazes de resolver outras questões? & & & 1 & 3 & 6 \\
\hline $\begin{array}{l}\text { Proposta de Avaliação: O(s) instrumento(s) de avaliação propostos são adequados? Os métodos } \\
\text { de avaliação são condizentes com os objetivos e conteúdos propostos? A avaliação é integrada ao } \\
\text { longo da ABP? Ou apresentada no final, ou seja, avalia-se todo o percurso do aluno ou a avaliação } \\
\text { é prioritariamente classificatória vinculada aos resultados a serem atingidos no produto final? }\end{array}$ & & & & & 10 \\
\hline $\begin{array}{l}\text { Originalidade da Proposta ABP: A proposta de ABP é original? Existem outras propostas muito } \\
\text { parecidas? É inovadora? }\end{array}$ & & & & 2 & 8 \\
\hline $\begin{array}{l}\text { Clareza e Inteligibilidade da Proposta: As explicações contidas no planeja mento da ABP são } \\
\text { suficientes para um entendimento do que é proposto? Está claro como esta deve ser aplicada em } \\
\text { sala de aula? }\end{array}$ & & & & 2 & 8 \\
\hline
\end{tabular}

Fonte: Compilado e elaborado pelas autoras (2019).

Após a análise dos resultados foi feito o planejamento das atividades a serem realizadas, conforme descrito no Apêndice A.

\subsection{RESPONSABILIDADES DADAS AOS ESTUDANTES}

Barrows e Tamblyn (1980) enfatizaram que a aplicação da ABP exige um mistura de fatores diretivos e não diretivos e técnicas de facilitação construídas em atitudes humanistas. Esta combinação é necessária para inspirar os alunos a colher os benefícios da investigação e 


\section{sala \\ de $\oplus$ em \\ aula foco}

pensamento de resolução de problemas, autonomia de aprendizagem, habilidades de aprendizagem autodirigidas, comunicação, trabalho em equipe, habilidades e aprendizagem ao longo da vida. Fatores estes semelhantes aos pontos fundamentais que devem ser observados na oferta da EJA segundo Di Pierro, Joia e Ribeiro (2001).

Procurou-se, no planejamento da ABP, incorporar atividades que levassem os alunos a serem mais ativos e a se responsabilizarem pela sua aprendizagem. Foram, então, utilizadas várias ferramentas como: Ficha de monitoramento da ABP para ajudar os alunos a identificar suas necessidades de aprendizagem para a resolução do problema; Ficha de auto e heteroavaliação, instrumento que fomenta o desenvolvimento de competências metacognitivas auxiliando o aluno a avaliar o seu desempenho e a sua colaboração com o grupo; Relatório orientado no grupo deve discutir e validar ideias bem como retroalimenta solução em um processo cooperativo e dialógico.

Figura 2 - Algumas imagens registradas durante o preenchimento da ficha de monitoramento da ABP.

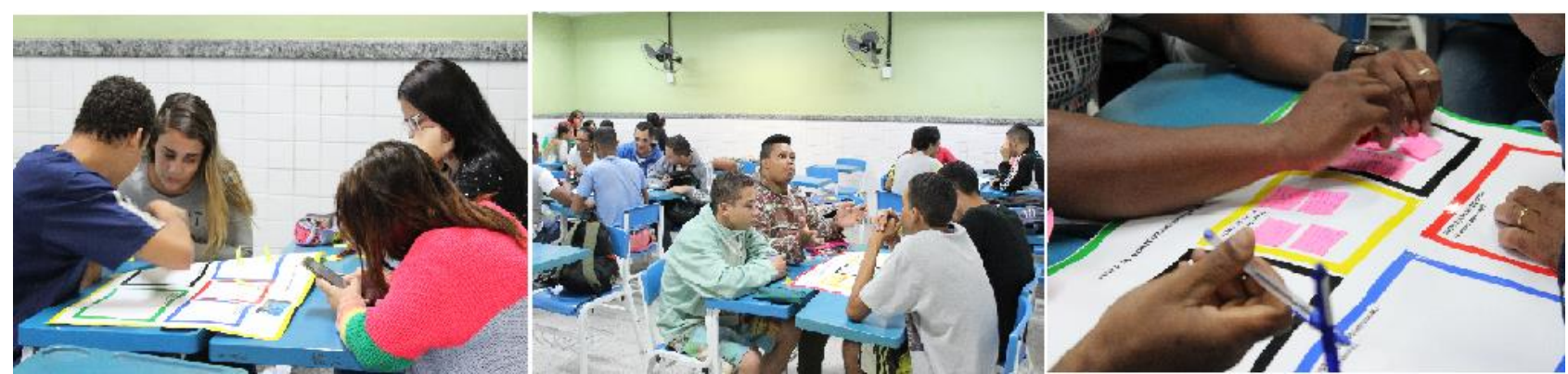

Fonte: Acervo das autoras (2019).

Além dos instrumentos descritos anteriormente foi utilizado Google Classroom, ambiente onde foram inserindo algumas fontes de pesquisa incluindo: vídeos, textos, imagens, revistas, blogs, reportagens, documentários, filmes relacionados a temática Terra e Universo na perspectiva do turismo espacial, etc. O Google Classroom foi utilizado como instrumento mediador, pois, além de promover a comunicação e interação entre os participantes da ABP pode tornar visível o pensamento do aluno, por exemplo, os alunos postam textos digitais como respostas a várias etapas da investigação, isso pode ajudar a revelar o que os alunos estão pesquisando, sendo útil para o professor provocar e abordar equívocos dos alunos. 


\section{sala \\ de $\theta$ - em \\ aula foco}

Por ser a ABP uma estratégia nova para os alunos, em um primeiro momento alguns demonstraram insatisfação e dificuldades, outros tiveram fizeram indagações sobre a tarefa. Além disso, os alunos demonstraram surpresa e curiosidade, quando o professor disse que eles utilizariam os chromebooks na sala com acesso à internet, e, que havia um para cada aluno utilizar nas próximas aulas.

\subsection{MÉTODOS DE AVALIAÇÃO}

A ABP requer diferentes tipos de ferramentas que avaliam a capacidade do aluno de trabalhar com problemas e aplicar a informação aprendida à sua compreensão ou resolução (BARROWS; TAMBLYN, 1980). O que pode proporcionar na EJA o aperfeiçoar dos mecanismos de avaliação facultando a valorização das aprendizagens adquiridas na experiência pessoal e/ou profissional (DI PIERRO; JOIA; RIBEIRO, 2001). Como visto no Quadro 3.

Quadro 3 - Descrição do tipo e critério de avaliação do aluno durante a aplicação da ABP.

\begin{tabular}{|c|c|}
\hline Instrumento de Avaliação & Critérios de Avaliação, (o aluno demonstra saber): \\
\hline $\begin{array}{l}\text { Ficha de monitoramento da } \\
\text { ABP }\end{array}$ & $\begin{array}{l}\checkmark \quad \text { Identificar o problema raiz; } \\
\checkmark \quad \text { Identificar o que precisam aprender para resolver o problema; } \\
\checkmark \quad \text { Colaborar e distribuir tarefas. }\end{array}$ \\
\hline $\begin{array}{l}\text { Construção e apresentação da } \\
\text { programação da viagem } \\
\text { espacial (texto) }\end{array}$ & $\begin{array}{l}\checkmark \text { Compartilhar o que aprendeu durante o estudo autodirigido; } \\
\checkmark \text { Aplicar o que aprenderam; } \\
\checkmark \text { Tomar decisão de grupo em relação ao problema; } \\
\checkmark \text { Verificar se o que pesquisou foi suficiente; } \\
\checkmark \quad \text { Utilizar o Google Classroom como fonte de pesquisa; } \\
\checkmark \text { Utilizar o Google Classroom como instrumento de interação institucional; } \\
\checkmark \quad \text { Utilizar o Google Classroom na edição compartilhada do texto; } \\
\checkmark \quad \text { Verificar a eficácia das estratégias empregadas. }\end{array}$ \\
\hline $\begin{array}{l}\text { Apresentação da programação } \\
\text { da viagem espacial (mídia) }\end{array}$ & $\begin{array}{l}\checkmark \quad \text { Comunicar o que aprenderam; } \\
\checkmark \quad \text { Produzir comunicação em mídia; } \\
\checkmark \quad \text { Utilizam o Google Classroom como meio digital de busca e fonte de } \\
\quad \text { pesquisa; } \\
\checkmark \quad \text { Utilizar o Google Classroom como instrumento de interação institucional. }\end{array}$ \\
\hline $\begin{array}{l}\text { Ficha de auto e } \\
\text { heteroavaliação }\end{array}$ & $\begin{array}{l}\checkmark \text { Autonomia do aluno em avaliar o seu próprio desem penho em colaboração } \\
\text { ao grupo; } \\
\quad \text { Maturidade do aluno de ser avaliado pelo seus pares. }\end{array}$ \\
\hline $\begin{array}{l}\text { Simulado bimestral (questão } \\
\text { envolvendo "uma viagem } \\
\text { espacial") }\end{array}$ & $\begin{array}{l}\checkmark \text { Linha de karman (questão de múltipla escolha com cinco alternativas, } \\
\text { contendo uma correta). }\end{array}$ \\
\hline Relatório orientado & $\begin{array}{ll}\checkmark & \text { Define um sistema de solução; } \\
\checkmark & \text { Coleta informações e dados; } \\
\checkmark & \text { Discute e valida ideias; } \\
\checkmark & \text { Desenvolve solução; } \\
\checkmark & \text { Retroalimenta solução. }\end{array}$ \\
\hline
\end{tabular}

Fonte: Elaborado pelas autoras (2019).

Os objetivos da ABP são baseados no conhecimento e no processo. Estudantes precisam ser 


\section{sala \\ de $\oplus$ - em \\ aula foco}

—REVISTA ELETRÔNICA

avaliados em ambas as dimensões em intervalos regulares para garantir que sejam beneficiados como pretendido. Munhoz (2015) conclui que na metodologia ABP os alunos devem ser incentivados a adotar a autoaprendizagem como forma de desenvolver um senso crítico e recuperar a criatividade, cerceada nos ambientes tradicionais.

\section{Conclusões}

A Aprendizagem Baseada em Problemas (ABP) é uma das estratégias pedagógicas associada às metodologias ativas de aprendizagem, que tem como foco a aprendizagem centrada no aluno e trabalhos colaborativos baseado em atividades de aprendizagem significativa que reflitam seus conhecimentos prévios.

Este trabalho apresenta a utilização da ABP no ensino de física em uma turma de EJA, o problema apresentado aos alunos foi intitulado "Uma Volta ao Espaço em Trinta Dias" teve como propósito oportunizar aos alunos o contato com uma metodologia diferenciada, aliada a utilização de uma sala de aula virtual com as tecnologias digitais associadas. Com isso procurou ensinar o aluno a aprender, incentivando a identificar o que é necessário saber diante do problema da ABP, pesquisar entre os diversos meios de informação, estimular o desenvolvimento do pensamento crítico e permitir ao aluno ser ativo no processo ensino-aprendizagem.

A ABP como estratégia pedagógica pode ajudar no enfrentamento dos desafios postos a EJA nos dias atuais ao aproximar-se da realidade social dos alunos, resgatando seus conhecimentos prévios, permitindo que estes tomem as rédeas do seu processo de aprendizagem e, preparando-os para a aprendizagem ao longo da vida.

O planejamento das aulas de ABP foi realizado seguindo os critérios descritos por Barrows e Tamblyn (1980), e isso representa uma estratégia de ensino que valoriza a autonomia do aluno, favorece a comunicação e a colaboração.

Problemas de ABP fornecem oportunidades de aprendizagem que vão além de apenas resolver o problema, aliada ao uso da tecnologia digital favorece o desenvolvimento de comportamentos e atitudes desejáveis aos alunos de Ciências da Natureza. 


\section{sala \\ de $\oplus$ em \\ aula foco}

Avaliamos a priori o nível de dificuldade do problema que desempenha um papel na eficácia do aluno, com base nos nove parâmetros analisados, o que indicou um nível apropriado para a aplicação do problema, resultando no envolvimento dos alunos.

Mapeamos o espaço global de aprendizagem, que indica os conhecimentos necessários para resolver o problema. Ficou claro, nessa pesquisa, que o problema de ABP pode permitir uma aprendizagem ampla, mas não pode garantir que todo o espaço global de aprendizagem seja coberto. No entanto mapear os possíveis conceitos discutidos no problema é importante porque prevê o desempenho do aluno.

Tratamos da responsabilidade dada aos alunos e observamos no decorrer das aulas, que foram academicamente independentes, sendo capaz de avaliar suas necessidades de objetivos, avaliar recursos e tomar decisões responsáveis, porém através de relatos percebemos a dificuldade na transição dos alunos para papéis mais ativos.

Importamos com a avaliação adequada a metodologia da ABP, para isso o aluno foi avaliado durante todo processo em diferentes recursos. Vale ressaltar o engajamento e a participação efetiva dos alunos durante as aulas, apresentando um comportamento ativo e participativo, incompatível com o comportamento habitual da turma.

Como apoio a metodologia da ABP criamos uma sala de aula virtual no Google Classroom, inserimos diversas fontes de dados previamente analisadas para contribuir na resolução do problema e tarefas para serem desempenhadas e entregues por meio digital.

Os alunos informaram que a fonte de dados do Google Classroom serviu como referência, facilitando a pesquisa. Verificamos também a realização das tarefas de forma colaborativa e simultânea.

No entanto a implementação da $\mathrm{ABP}$ requer mais do que um desejo de inovar. Requer um compromisso com uma mudança no formato de aprendizagem. Mais pesquisas são necessárias, em 


\section{sala \\ de $\oplus$ em \\ aula foco}

várias áreas de conteúdos em diferentes níveis de ensino, para determinar como a ABP pode melhorar o processo de aprendizagem dos alunos usando a tecnologia como apoio.

\section{REFERÊNCIAS}

AMADO, Manuella Villar. Contributos da Aprendizagem Baseada na Resolução de Problemas na Educação para o Desenvolvimento Sustentável em Espaços de Educação não Formal. Relatório de Pós-Doutoramento. Porto: Faculdade de Ciências da Universidade do Porto. 2014.

BARROWS, Howard. S.; TAMBLYN, Robyn. M. Problem-Based Learning an Approach to Medical Education. New York: Springer Publishing Company, ed.1, 1980.

CAPLOW, J.; DONALDSON, J.; KARDASH, C.; HOSOKAWA, M. Learning in a problem-based medical curriculum: Students' conceptions. Medical education, v. 30, p. 440-447, 1997.

DI PIERRO, Maria Clara; JOIA, Orlando; RIBEIRO, Vera Masagão. Visões da Educação de Jovens e Adultos no Brasil. Caderno Cedes, Campinas, ano XXI, n. 55, p. 58-77, 2001.

MATTAR João. Metodologias Ativas: para a educação presencial, blended e a distância. São Paulo: Artesanato Educacional. 2017.

MUNHOZ, Antonio Siemsen. ABP: Aprendizagem Baseada em Problemas: Ferramenta de apoio ao docente no processo de ensino e aprendizagem. São Paulo: Cengage Learning, 2015.

SILVA, Natalino Neves da. Educação de Jovens e Adultos : alguns desafios em torno do direito à educação. PAIDÉIA, v. 7, p. 61-72, 2009.

WALKER, Andrew; LEARY, Heather; HMELO-SILVER, Cindy; ERTMER, Peggy. Essential Readings in Problem-Based Learning: Exploring and Extending the Legacy of Howard S. Barrows. West Lafayette: Purdue University Press, 2015. 


\section{sala \\ de

\section{APÊNDICE A - CRONOGRAMA E ATIVIDADES A SEREM DESENVOLVIDA DURANTE A INTERVENÇÃO ESCOLAR.}

\begin{tabular}{|c|c|c|}
\hline Aula & Local/Duração & Atividades desenvolvidas. \\
\hline 01 & $\begin{array}{c}\text { Sala de aula } \\
1 \mathrm{~h}\end{array}$ & $\begin{array}{l}\checkmark \text { Apresentação do projeto intitulado "Uma Volta ao Espaço em Trinta dias"; } \\
\checkmark \text { Autorização por meio da assinatura dos TCLE; } \\
\checkmark \text { Apresentação da reportagem 'Turismo espacial: Cápsula da SpaceX é testada com } \\
\text { sucesso (duração: } 4 \text { minutos). }\end{array}$ \\
\hline $\mathrm{O} 2$ & $\begin{array}{l}\text { Auditório; } \\
\text { Pátio escolar } \\
\text { não coberto } \\
\quad 1 \mathrm{~h}\end{array}$ & $\begin{array}{l}\checkmark \text { Contextualização problemática com exploração didática do cenário; } \\
\checkmark \text { Apresentação da palestra sobre o 'Sistema Sol-Terra-Lua' mostrando as estações do } \\
\text { ano, as fases da lua e os eclipses, complementando com o aplicativo de pla netário } \\
\text { Stellarium (duração: } 30 \text { minutos); } \\
\checkmark \quad \text { Vivência com o telescópio. }\end{array}$ \\
\hline 03 & $\begin{array}{c}\text { Sala de aula } \\
1 \mathrm{~h}\end{array}$ & $\begin{array}{ll}\checkmark & \text { Apresentação do problema de ABP; } \\
\checkmark & \text { Conversa sobre o problema lançado para identificar possíveis dúvidas; } \\
\checkmark & \text { Organização dos grupos. }\end{array}$ \\
\hline 04 & $\begin{array}{c}\text { Sala de aula } \\
1 \mathrm{~h}\end{array}$ & $\begin{array}{l}\checkmark \text { Orientações sobre a ficha de monitoramento da ABP e início do seu preenchimento; } \\
\checkmark \text { Orientações para o estudo individual extraclasse de acordo com a primeira análise que } \\
\text { cada grupo fez do cenário. }\end{array}$ \\
\hline 06 & $\begin{array}{c}\text { Sala de aula } \\
1 \mathrm{~h}\end{array}$ & $\begin{array}{l}\checkmark \text { Utilizar o formulário google docs para preencher a proposta, programação da viagem } \\
\text { espacial; } \\
\checkmark \quad \text { Atendimento individualizado da professora aos grupos para orientação. }\end{array}$ \\
\hline 07 & $\begin{array}{c}\text { Sala de aula } \\
1 \mathrm{~h}\end{array}$ & $\begin{array}{l}\checkmark \text { Retorno ao formulário do google docs, programação da viagem espacial, finalização do } \\
\text { documento. } \\
\checkmark \text { Atendimento individualizado da professora aos grupos para orientação. } \\
\checkmark \text { Apresentação da proposta no google docs. }\end{array}$ \\
\hline EAD & $\begin{array}{c}\text { Google } \\
\text { Classroom }\end{array}$ & $\begin{array}{l}\checkmark \text { Utilizar um editor gratuito para criar a apresentação da programação da viagem } \\
\text { espacial em mídia (vídeo, áudio ou mapa mental) para publicação em rede social: } \\
\text { twitter, facebook, instagram. }\end{array}$ \\
\hline
\end{tabular}

Fonte: Elaborada pelas autoras (2019). 